\title{
Røyking og kronisk obstruktiv lungesykdom hos menn bosatt i Bergen
}

\author{
Sjur Humerfelt og Amund Gulsvik \\ Lungeavdelingen, Haukeland Sykehus, Universitetet i Bergen, 5021 Bergen \\ Korrespondanse: Dr. Sjur Humerfelt, Tlf. 55298060 - calling: 4075; Fax: 55975149 / 55974049
}

\begin{abstract}
SAMMENDRAG
Formålet med denne kohortstudien var å undersøke sammenhengen mellom røyking, tidlig død og redusert lungefunksjon hos menn over en 23 års periode. Et tilfeldig utvalg på 1933 personer i alderen 22-54 år bosatt i Bergen i perioden 1965-70 ble invitert til en helseundersøkelse, hvorav 1591 menn deltok (82\%). Personer i utvalget som fortsatt bodde i Bergen i 1988-90 (1154 menn) ble invitert til en oppfølgingsundersøkelse. Målinger av lungefunksjonen og opplysninger om røykevaner ble innhentet ved begge undersøkelsene. Lungefunksjonen ble målt som det forserte utåndings-

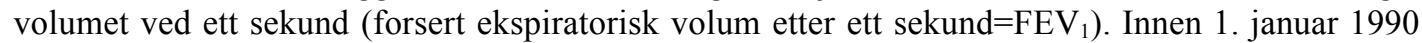
var 303 personer døde blant de fremmøtte fra den første undersøkelsen, mens tilsammen 1063 menn møtte til andre gangs undersøkelse, hvorav $90 \%$ hadde komplette data fra begge tidspunkt. Den

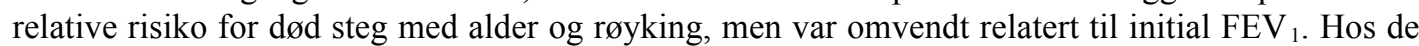
gjenlevende ble den gjennomsnittlige årlige forandring $\mathrm{i} \mathrm{FEV}_{1}$ beregnet på grunnlag av forskjellen $\mathrm{i}$ $\mathrm{FEV}_{1}$ på de to tidspunkt og angitt i ml/år. I hele aldersgruppen falt $\mathrm{FEV}_{1}$ gjennomsnittlig (SD) 53 (18) $\mathrm{ml} /$ år og økte gradvis med alder og kroppshøyde. Fallet i $\mathrm{FEV}_{1}$ var lavest blant aldri-røykere og $ø k$ te gradvis med antall sigaretter røykt daglig. Personer som hadde sluttet å røyke hadde et fall $\mathrm{i}$ $\mathrm{FEV}_{1}$ tilsvarende nivået hos aldri-røykere. I denne prospektive undersøkelsen blant menn bosatt $\mathrm{i}$ Bergen fant vi en sterk sammenheng mellom røyking og tidlig død, og hos dem som var i live etter 23 år et økende fall i lungefunksjonen med antall sigaretter røykt.
\end{abstract}

Humerfelt S, Gulsvik A. Smoking and chronic obstructive lung disease among men in Bergen. Nor J Epidemiol 1995; 5 (2): 129-134.

\section{ENGLISH SUMMARY}

The purpose of this 23 years community follow-up survey of men aged 22-54 years $(n=1933)$ in Bergen, Norway, was to evaluate the effects of smoking on mortality and decline in $\mathrm{FEV}_{1}$ among the survivors. Smoking habits and measurements of $\mathrm{FEV}_{1}$ were recorded at the initial survey in 1965-70 $(\mathrm{n}=1591)$ and at follow-up in 1988-90 $(\mathrm{n}=951)$. At follow-up altogether 303 subjects had died. The crude mortality rate increased with age and cigarette consumption and was inversely related to initial $\mathrm{FEV}_{1}$ level. Among the survivors the decline in $\mathrm{FEV}_{1}$ was associated $(\mathrm{p}<0.001)$ with age, body height and smoking. Smoking cessation reduced the decline to the level of never smokers. Smoking was found to be an important predictor for early mortality and accelerated decline in FEV $\mathrm{FE}_{1}$ in male adults from the general community.

\section{INNLEDNING}

Kronisk obstruktiv lungesykdom (KOLS) er en tilstand preget av trange luftveier som gir en patologisk høy motstand mot luftstrømmen (1). Hovedkarakteristikken ved KOLS er således en kronisk luftstrømsobstruksjon som utvikler seg gradvis over flere år og som går over i en progredierende irreversibel tilstand med redusert forsert ekspiratorisk volum ved ett sekund $\left(\mathrm{FEV}_{1}\right)$. KOLS brukes ofte som et samlebegrep for emfysem og kronisk obstruktiv bronkitt (2).

De fleste epidemiologiske studier av risikofaktorer for KOLS baserer seg på tverrsnittsundersøkelser som bare kan antyde samvariasjon og ikke sikker årsaks- 
sammenheng mellom eksponering og lungesykdommer. Slike undersøkelser i Oslo i 1973-74 viste at 4,1\% av befolkningen i alderen 16-69 år hadde KOLS (3) mens 5,4\% i samme aldersgruppe hadde KOLS i 1987-88 i Bergen og 11 omkringliggende kommuner (4). I begge studiene ble KOLS definert som personer med ett eller flere symptomer som kronisk hoste, oppspytt ved hoste, tungpusthet og piping i brystet, og som dessuten hadde $\mathrm{FEV}_{1} / \mathrm{FVC}$ mindre enn $70 \%$. Selv om tobakksrøyking er den viktigste risikofaktor for utvikling av KOLS (5), er patogenesen ikke klarlagt. Det foreligger få longitudinelle studier som har undersøkt forandringene $\mathrm{i} \mathrm{FEV}_{1}$ og utviklingen av kronisk obstruktiv lungesykdom. Studier fra selekterte yrkesgrupper har svakheter ved at det skjer en seleksjon inn eller ut av yrket $(5,6)$. Longitudinelle studier fra generelle befolkninger er hittil bare utført med oppfølgingsperioder på mindre enn 13 år (7).
I denne kohortstudien over 23 år ønsket vi derfor å estimere fallet i lungefunksjon, bedømt ved fallet $i$ $\mathrm{FEV}_{1}$, og å estimere dødeligheten $\mathrm{i}$ denne perioden relatert til røykevanene.

\section{UTVALG OG METODE}

Den første undersøkelsen baserte seg på et tilfeldig utvalg av menn bosatt i Bergen pr. 1. januar 1964 og født i perioden 1914-43 ( $n=1933)$. Dette utvalget ble $i$ 1965-70 invitert til Blodtrykksundersøkelsen i Bergen, hvorav $82 \%$ møtte etter to purringer (figur 1). Informasjon om røykevaner ble innhentet via standardiserte intervju foretatt av sykepleiere og $\mathrm{FEV}_{1}$ målinger ble utført med Vitalograph belg-spirometre.

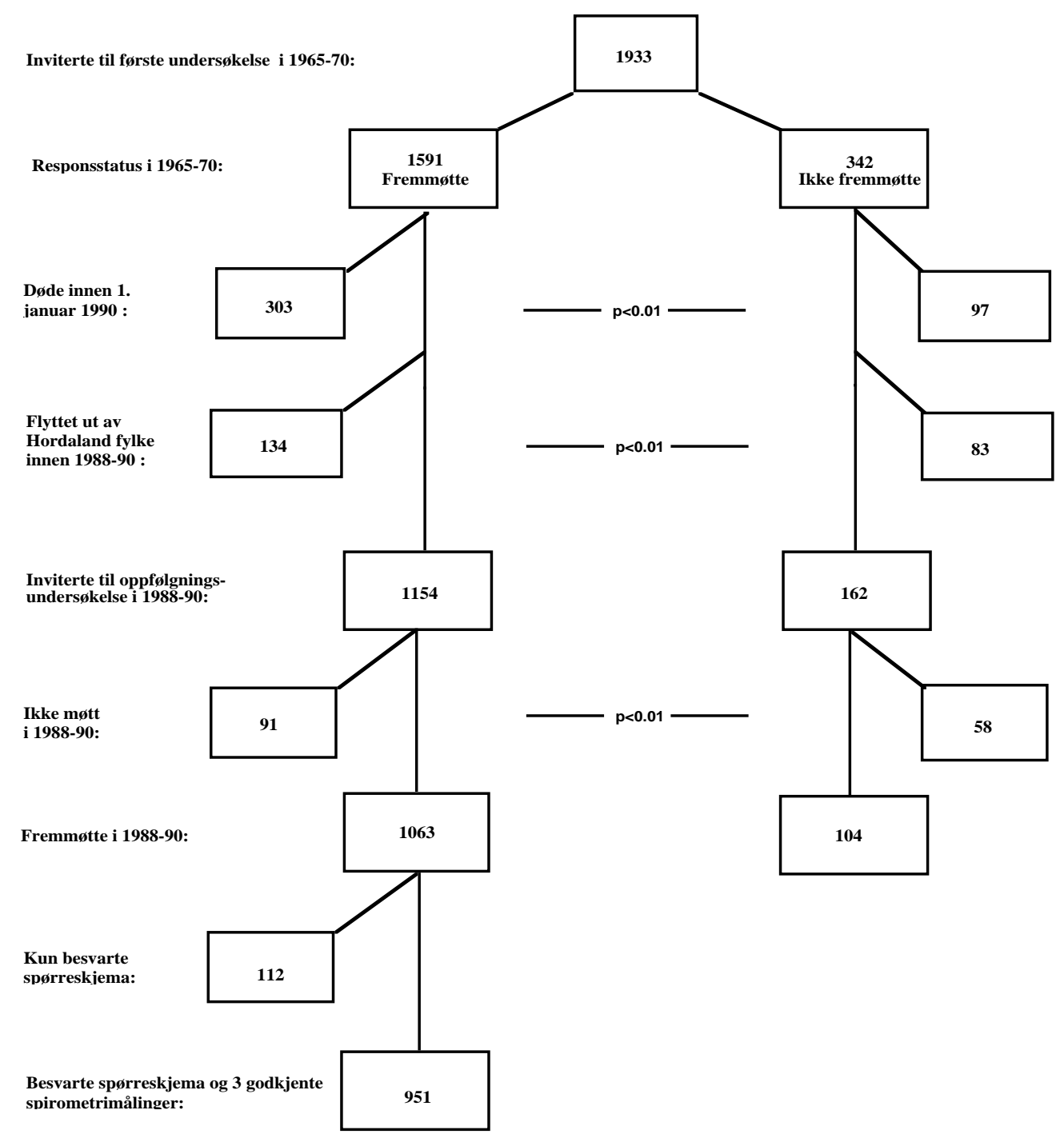

Figur 1. Utvalgets responsstatus ved begge undersøkelsene. P-verdiene angir signifikansnivåene på forskjellene i dødelighet, utflytting og andregangs fremmøte blant inviterte til første undersøkelse. 
En oppfølgingsundersøkelse ble gjennomført i perioden 1988-90 blant personer i utvalget som fortsatt var bosatt i Bergen ( $n=1154)(8)$. Røykevanene ble innhentet via spørreskjema og målinger av $\mathrm{FEV}_{1}$ og forsert ekspiratorisk vitalkapasitet (FVC) ble utført med samme type belgspirometre som ved den første undersøkelsen. I alt møtte 1063 personer fra første undersøkelse, hvorav $90 \%$ hadde komplette data fra begge tidspunkt. Den gjennomsnittlige årlige forandring i $\mathrm{FEV}_{1}$ ble beregnet på grunnlag av forskjellen i $\mathrm{FEV}_{1}$ ved de to undersøkelsene og uttrykt i ml/år. Vi definerte spirometrisk luftstrømsobstruksjon som $\mathrm{FEV}_{1} / \mathrm{FVC}$ mindre enn $65 \%$ ved oppfølgingsundersøkelsen.

Opplysninger om dødsfall og emigrasjon blant utvalget ble innhentet fra Folkeregisteret i Bergen og Statens helseundersøkelser. I alt var $27 \%$ av utvalget som møtte til den første undersøkelsen ikke tilgjengelig for oppfølging og inkluderte 303 døde og 134 personer som hadde flyttet ut av området (figur 1).

\section{Statistiske metoder}

Analysene ble utført ved hjelp av programpakken fra BMDP (9). Uparrede t-tester ble benyttet for å sammenligne gjennomsnittsverdier, mens forskjeller $\mathrm{i}$ prevalens ble testet ved hjelp av kjikvadrat-teknikk. Sammenligning av gjennomsnittsverdier justert for andre kovariabler ble utført ved hjelp av enveis kovarians analyser.

\section{RESULTATER}

Figur 1 viser utvalgets responsstatus ved begge undersøkelsene. De fremmøtte ved første undersøkelse hadde mindre dødelighet og utflytting fra området før oppfølgingsundersøkelsen enn de ikke-fremmøtte, med hhv. $19 \%$ versus $28 \%$ dødelighet og $8 \%$ versus $24 \%$ utflytting. Figuren viser også at fremmøtet ved oppfølgingsundersøkelsen var størst blant personene som hadde møtt til første undersøkelse; 92\% versus $64 \%$ blant de ikke fremmøtte. Fremmøtte ved begge undersøkelsene $(\mathrm{n}=951)$ hadde identisk initial alder med alle som møtte på den første undersøkelsen $(n=1591)$, med en gjennomsnittsalder (SD) på 38 (9) år. Disse gruppene var yngre enn dem som hadde dødd (gjennomsnittsalder (SD) = 44 (7) år), men eldre enn dem som ikke var tilgjengelig (134 personer hadde flyttet og 91 møtte ikke) for oppfølging (gjennomsnittsalder (SD) $=34$ (8) år). Personene som møtte til den andre undersøkelsen hadde en gjennomsnittsalder på 61 (spredning: 46-76) år etter en gjennomsnittlig oppfølging på 23 (spredning: 20-25) år.

Røykevanene hos deltagerne som møtte på begge undersøkelsene var identiske med røykevanene hos alle som møtte til første undersøkelse og bestod av $19 \%$ aldri-røykere, $15 \%$ ex-røykere og 66\% røykere. Andelen røykere sank til 39\% ved andre undersøkelse, mens andelen ex-røykere steg tilsvarende (tabell 1). Fra tabell 1 ser vi også at andelen storrøykere $(\geq 15$ sigaretter/dag) blant røykerne steg fra $14 \%$ til $45 \%$ og gjennomsnittlig (SD) antall sigaretter/dag steg fra 11 (6) ved første undersøkelse til 15 (7) ved andre undersøkelse.

Dødeligheten blant de fremmøtte etter den første undersøkelsen er vist $\mathrm{i}$ tabell 2 . Den relative risiko for død steg med økende alder og røyking. Dødeligheten var også omvendt relatert til initial $\mathrm{FEV}_{1}$ og var 2,5 ganger høyere hos menn med $\mathrm{FEV}_{1}<70 \%$ av forventet verdi sammenlignet med dem som hadde $\mathrm{FEV}_{1} \geq 100 \%$.

$\mathrm{FEV}_{1}$ falt i gjennomsnitt (SD) med 53 (18) ml/år i hele utvalget og dette fallet økte gradvis med alder og kroppshøyde $(\mathrm{p}<0.01)$. Fallet i $\mathrm{FEV}_{1}$ var lavest blant aldri-røykerne og økte gradvis med antall sigaretter røykt daglig $(\mathrm{p}<0.01)$ (figur 2$)$. Menn som hadde sluttet å røyke forut for den første undersøkelsen hadde et fall i FEV 1 tilsvarende nivået hos aldrirøykerne, mens menn som sluttet å røyke mellom de to undersøkelsene hadde et fall $\mathrm{i} \mathrm{FEV}_{1}$ mellom det som var observert hos røykere og aldri-røykere. Pipeog sigar-røykere $(n=35)$ hadde et fall i $\mathrm{FEV}_{1}$ (gjennomsnitt: $58 \mathrm{ml} /$ år) tilsvarende fallet hos sigarett-røykerne.

Tabell 1. Røykevaner hos fremmøtte ved første undersøkelse i 1965-70 og ved oppfølgningen i 1988-90.

\begin{tabular}{lcc} 
& \multicolumn{2}{c}{ Fremmøtte ved begge undersøkelsene } \\
& \multicolumn{2}{c}{ N=1063 } \\
\cline { 2 - 3 } & $\begin{array}{cc}\text { Første undersøkelse, } \\
1965-70\end{array}$ & $\begin{array}{c}\text { Andre undersøkelse, } \\
\end{array}$ \\
Røykevaner: & $\%$ & $1988-90$ \\
\hline Aldri-røykere: & 18 & 18 \\
Ex-røykere: & 15 & 39 \\
Røykere: & 67 & 39 \\
< 15 sigaretter/dag & 49 & 19 \\
> 15 sigaretter/dag & 9 & 17 \\
Pipe/sigar & 7 & 3 \\
\hline
\end{tabular}




\section{Røykegrupper:}

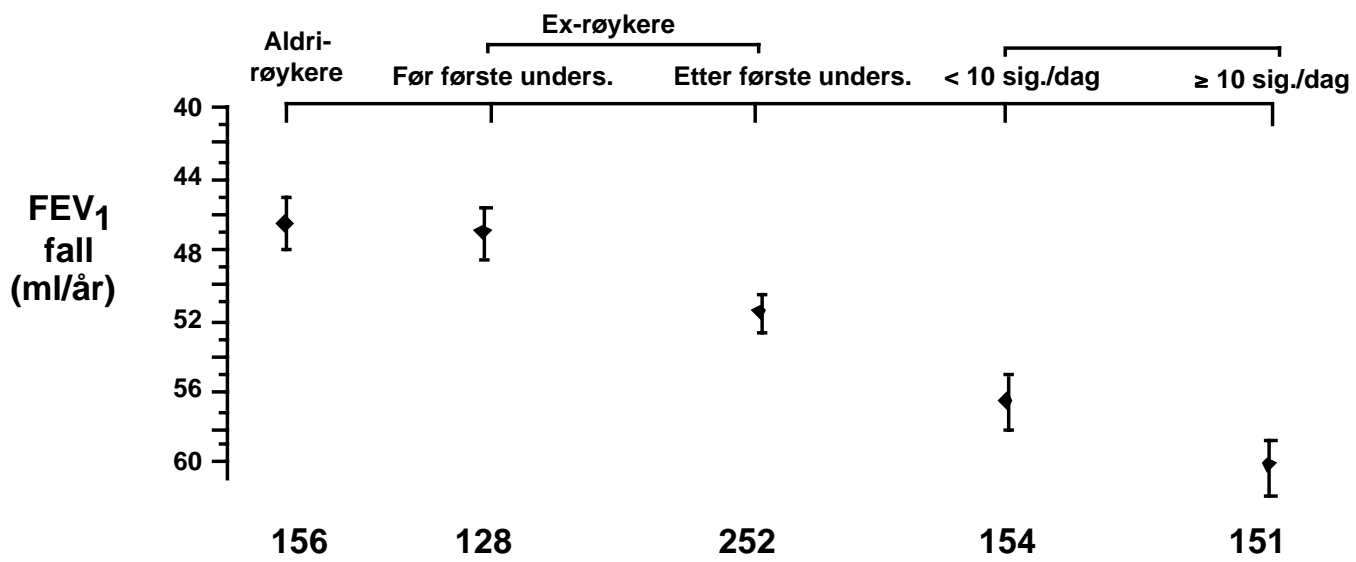

Figur 2. Fallet i $\mathrm{FEV}_{1}$ (mean, SEM) i ml/år ved ulike røykevaner.

Forekomsten av spirometrisk luftstrømsobstruksjon var 9,5\% og andelen økte med alderen og antall sigaretter røykt daglig (figur 3). Faktisk var det ingen aldri-røykere (av ialt 156 menn) med slike spirometrifunn, mens ialt $21 \%$ av sigarett-røykerne hadde slike spirometri-verdier.

\section{DISKUSJON}

I denne prospektive undersøkelsen blant menn bosatt i Bergen fant vi en sterk sammenheng mellom røyking og tidlig død samt et større fall i lungefunksjonen og utvikling av spirometrisk luftstrømsobstruksjon hos røykere som var i live etter 23 år.

Våre funn er i overenstemmelse med nyere internasjonale studier som bekrefter tidligere observasjoner om at sigarettrøyking er den viktigste påvirkbare årsak til død i den industrialiserte del av verden (10). I
1985 forårsaket sigarettrøyking 35\% av alle dødsfallene hos menn i alderen 35-69 år. Samtidig har andre studier vist at røykestopp har gunstig effekt både på sykelighet og dødelighet fra hjerte-karsykdommer, KOLS og kreftsykdommer (11-13).

Hos menn undersøkt over en 23-års periode fant vi at det årlige fallet i $\mathrm{FEV}_{1}$ var 30\% større hos røykere av $\geq 10$ sigaretter/dag enn hos aldri-røykere. Tidligere har vi funnet at utgangsnivået av $\mathrm{FEV}_{1}$ (fra første undersøkelse) var $300 \mathrm{ml}$ lavere hos røykere enn hos aldri-røykere (8), noe som ytterligere forsterker risikoen for tidlig utviking av KOLS hos røykere. Studien viste også at røykestopp var gunstig med hensyn på et redusert fall i lungefunksjonen, enten røykestopp skjedde tidlig (før første undersøkelse) eller sent (innen andre undersøkelse). Tilsvarende er påvist i flere oppfølgingsstudier fra generelle befolkninger fra Danmark, Polen og USA $(7,14,15)$.

Tabell 2. Døde/1000, døde/1000/år $(23,2)$ og relativ risiko (RR) med 95\% konfidensintervall (95\% KI) for død innen 1 . januar 1990 mot alder og røykevaner blant fremmøtte ved første undersøkelse i 1965-70.

\begin{tabular}{cccccccc}
\hline Døde & Levende & Døde & Døde & & \\
$(\mathrm{N}=303)$ & $(\mathrm{N}=1288)$ & $/ 1000$ & $(95 \% \mathrm{KI})$ & $/ 1000 / \mathrm{år}$ & $(95 \% \mathrm{KI})$ & $\mathrm{RR}$ & $(95 \% \mathrm{KI})$ \\
\hline
\end{tabular}

\begin{tabular}{|c|c|c|c|c|c|c|c|c|}
\hline \multicolumn{9}{|l|}{ Alder: } \\
\hline $22-29$ år & 14 & 351 & 38 & $18-59$ & 2 & $1-3$ & 1 & - \\
\hline 30 - 39 år & 60 & 411 & 127 & $95-160$ & 6 & $4-7$ & 3 & $2-6$ \\
\hline 40 - 49 år & 150 & 443 & 253 & $213-294$ & 11 & $9-13$ & 6 & $5-9$ \\
\hline $50-54$ år & 79 & 83 & 488 & $380-595$ & 21 & $16-26$ & 12 & $7-22$ \\
\hline \multicolumn{9}{|l|}{ Røykevaner: } \\
\hline Aldri-røykere & 26 & 257 & 92 & $57-127$ & 4 & $2-6$ & 1 & - \\
\hline Ex-røykere & 41 & 203 & 168 & $117-219$ & 7 & $5-10$ & 2 & $1-3$ \\
\hline \multicolumn{9}{|l|}{ Røykere: } \\
\hline$<10$ sigaretter/dag & 166 & 624 & 210 & $178-243$ & 9 & $8-11$ & 2 & $2-3$ \\
\hline$\geq 10$ sigaretter/dag & 47 & 116 & 288 & $206-371$ & 12 & $9-6$ & 3 & $2-5$ \\
\hline Pipe/sigar & 22 & 88 & 200 & $116-284$ & 9 & $5-12$ & 2 & $1-4$ \\
\hline
\end{tabular}


Forskjeller i alderssammensetning og definisjoner av KOLS gjør det vanskelig å sammenligne den observerte forekomsten av spirometrisk luftstrømsobstruksjon på 9,5\% i vår studie med funn fra andre generelle befolkninger. På den andre siden er våre observasjoner konsistente med funn fra andre undersøkelser hvor samme objektive kriterier for spirometrisk luftstrømsobstruksjon er brukt. I slike studier fra Norge (4), Australia (16), Finland (17) og Polen (7) varierer forekomsten blant menn over 45 år mellom 4-11\%.

\section{Den aldersmessige utvikling av lungefunksjonen (FEV $\left.V_{1}\right)$}

Det er generelt akseptert at $\mathrm{FEV}_{1}$ stiger med økende alder til et platå omkring 30-års alderen (18) (figur 4).
Platået holder seg til omkring 40-års alderen og deretter faller $\mathrm{FEV}_{1} \mathrm{i}$ et akselererende tempo med økende alder (Kurve A i figur 3). Faktorer som påvirker disse ulike fasene av $\mathrm{FEV}_{1}$ vil kunne føre til at et individ får en redusert $\mathrm{FEV}_{1}$ og tilhørende øket risiko for utvikling av KOLS senere i livet. I likhet med flere andre studier har vi i denne artikkelen vist at sigarettrøyking

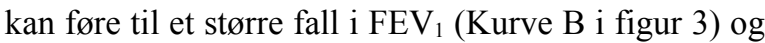
redusert $\mathrm{FEV}_{1}$ platå (Kurve C i figur 3). Astma (19), luftveisinfeksjoner (20) eller aktiv røyking (21) i ung alder kan også føre til redusert vekst av $\mathrm{FEV}_{1}$ (Kurve D i figur 3). Sigarettrøyking med debut i ungdomsårene er spesielt skadelig for utviklingen av $\mathrm{FEV}_{1}$ ved at kombinasjoner av kurvene $\mathrm{B}, \mathrm{C}$ og D i figur 4 kan opptre hos en og samme person.
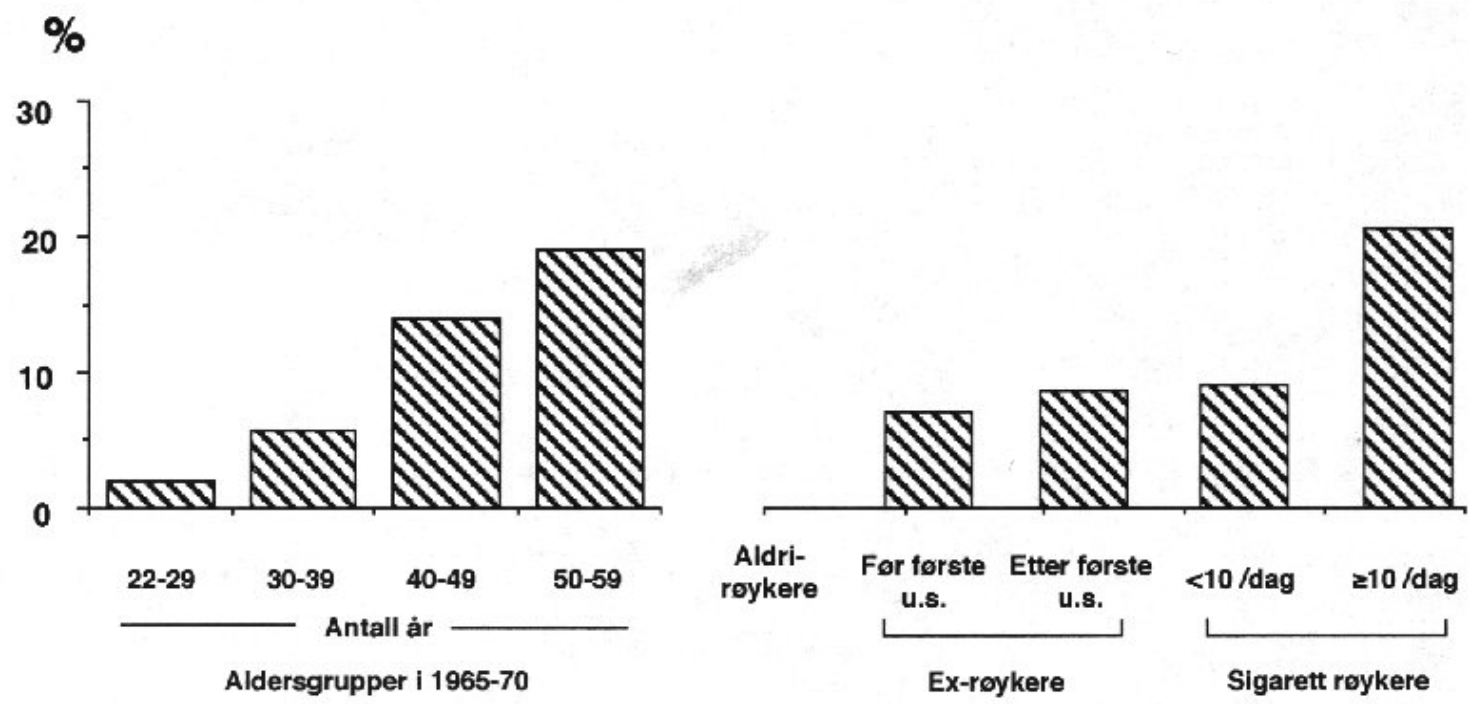

Figur 3. Forekomsten av spirometrisk luftstrømsobstruksjon $\left(\mathrm{FEV}_{1} / \mathrm{FVC}<65 \%\right)$ ved oppfølgingsundersøkelsen i 1988-90 relatert til alder i 1965-70 og røyking.

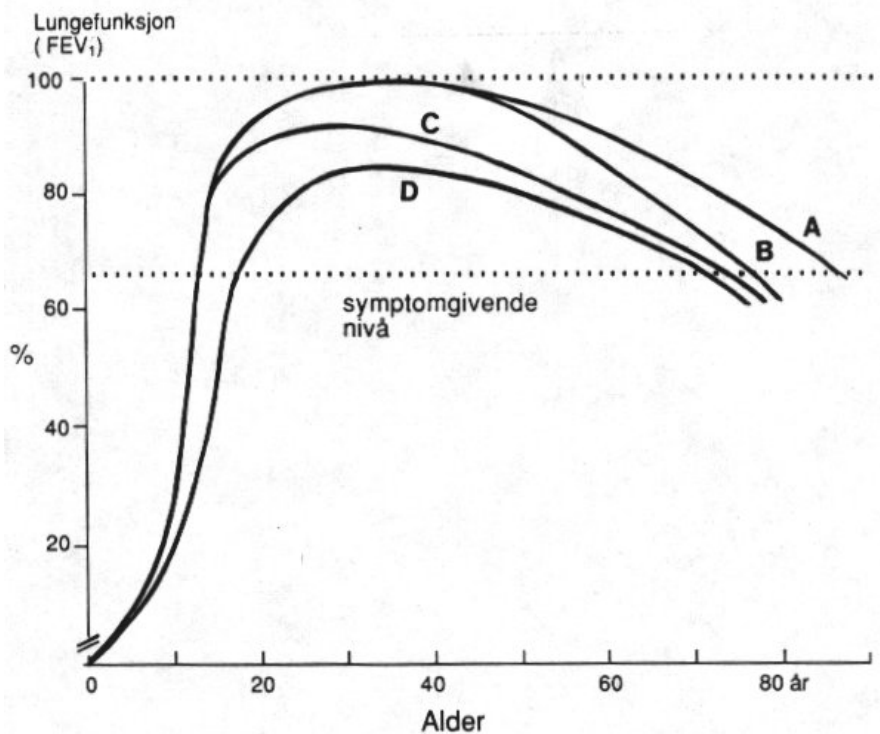

Figur 4. Utviklingen av $\mathrm{FEV}_{1}$ med alder. Kurve A: normal, aldri-røyker; Kurve B: raskt fall i $\mathrm{FEV}_{1}$ etter et platå; Kurve C: Intet platå; Kurve D: Lavt maksimalt nivå. 


\section{Roykestopp}

KOLS blir ofte diagnostisert sent i forløpet av sykdommen hos pasienter med lite symptomer selv med lave $\mathrm{FEV}_{1}$-verdier (22). Masseundersøkelser med spirometri er derfor nyttig for å diagnostisere KOLS tidlig $(23,24)$. Røykestopp er hittil det eneste kjente tiltaket som kan redusere fallet $\mathrm{FEV}_{1}$. I en randomi- sert røykestopp-studie blant menn fra den generelle befolkningen med redusert $\mathrm{FEV}_{1}$ og asbesteksposisjon har vi tidligere funnet at selv et enkelt og billig tiltak som et informasjonsbrev fra lege med brosjyre om røykestopp hadde signifikant $(\mathrm{p}<0.01)$ effekt på røykeslutt etter 12 måneder; $14 \%$ sluttet å røyke i intervensjonsgruppen mot 10\% i kontrollgruppen (25).

\section{REFERANSER}

1. Fletcher CM, Gilson JG, Hugh-Jones P, Scadding JG. Terminology, definitions and classification of chronic pulmonary emphysema and related conditions. Thorax 1959; 14: 286-299.

2. Gulsvik A. Definisjoner og diagnostiske kriterier ved obstruktiv lungesykdom (astma). Lungeforum 1995; 3: 4-8.

3. Gulsvik A. Prevalence and manifestations of obstructive lung disease in the city of Oslo. Scand J Resp Dis 1979; 60: 286-296.

4. Bakke P, Baste V, Hanoa R, Gulsvik A. Prevalence of obstructive lung disease in a general population: relation to occupational title and exposure to some airborne agents. Thorax 1991; 46: 863-870.

5. Fletcher C, Peto R, Tinker C, Speizer FE. The natural history of chronic bronchitis and emphysema. Oxford: Oxford University Press, 1976.

6. Kauffmann F, Drouet D, Lellouch J. Twelve years spirometric changes among Paris area workers. Int J Epidemiol 1979; 8: 201-212.

7. Krzyzanowski M, Jedrychowski W, Wysocki M. Factors associated with the change in ventilatory function and the development of chronic obstructive pulmonary disease in a 13 year follow-up of the Cracow study. Am Rev Respir Dis 1986; 134: 1011-1019.

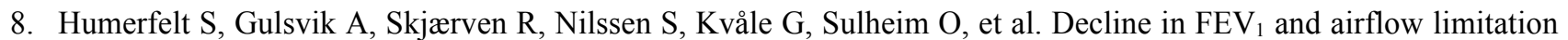
related to occupational exposures in men of an urban community. Eur Respir J 1993; 6: 1095-1103.

9. Dixon JW. BMDP Statistical Software Manual. Berkeley: University of California Press, 1990.

10. Peto R. Smoking and death: the past 40 years and the next 40. Br Med J 1994; 309: 937-939.

11. U.S. Department of Health and Human Services. The health benefits of smoking cessation. A report of the Surgeon General. U.S. Department of Health and Human Services, Public Health Services, Office on Smoking and Health, 1990.

12. Tverdal A, Thelle D, Stensvold I, Leren P, Bjartveit K. Mortality in relation to smoking history: 13 years follow-up of 68,000 Norwegian men and women 35-49 years. J Clin Epidemiol 1993; 46: 475-487.

13. Doll R, Peto R, Wheatley K, Gray R, Sutherland I. Mortality in relation to smoking: 40 years` observations on male british doctors. Br Med J 1994; 309: 901-911.

14. Bosse R, Sparrow D, Rose C, Weiss ST. Longitudinal effect of age and smoking cessation on pulmonary function. Am Rev Respir Dis 1981; 123: 378-381.

15. Lange P, Groth S, Nyboe J, Mortensen J, Appleyard M, Jensen G, Schnohr P. Effects of smoking and changes in smoking habits on the decline of $\mathrm{FEV}_{1}$. Eur Respir $J$ 1989; 2: 811-816.

16. Peat JK, Woolcock AJ, Cullen K. Decline of lung function and development of chronic airflow limitation: a longitudinal study of non-smokers and smokers in Brusselton, Western Australia. Thorax 1990; 45: 32-37.

17. Huhti E, Ikkala J. A 10 year follow-up study of respiratory symptoms and ventilatory function in a middle-aged rural population. Eur J Respir Dis 1980; 61: 33-45.

18. Sherrill DL, Camilli A, Lebowitz MD. On the temporal relationships between lung function and somatic growth. $\mathrm{Am}$ Rev Respir Dis 1989; 140: 638-644.

19. Weiss ST, Segal NM, Tager IB, Tosteson T, Redline S, Speizer FE. Effects of asthma on pulmonary function in children: a longitudinal population-based study. Am Rev Respir Dis 1992; 145: 58-64.

20. Gold D, Tager IB, Weiss ST, Tosteson T, Speizer FE. The relationship of acute respiratory illness to level and growth of lung function. Am Rev Respir Dis 1989; 140: 877-884.

21. Tager IB, Munoz A, Rosner B, Weiss ST, Carey V, Speizer FE. Effect of cigarette smoking on the pulmonary function of children and adolescents. Am Rev Respir Dis 1985; 131: 752-759.

22. Siafakas NM, Vermeire P, Pride NB, Paoletti P, Gibson J, Howard P, et al. Optimal assessment and management of chronic obstructive pulmonary disease (COPD). Eur Respir J 1995; 8: 1398-1420.

23. Anthonisen NR, Connett JE, Kiley JP, Altose MD, Bailey WC, Buist AS, et al. Effects of smoking intervention and

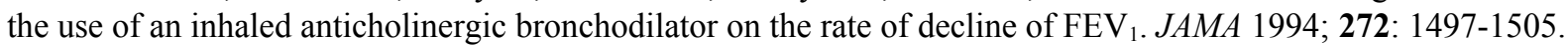

24. Humerfelt S, Eide GE, Kvåle G, Gulsvik A. Predictors of spirometric test failure: a comparison of the 1983 and 1993 acceptability criteria from the European Community for Coal and Steel. Occup Environ Med 1995;52:547-553.

25. Humerfelt S, Eide GE, Kvåle G, Årø LE, Gulsvik A. Smoking cessation after a doctor's postal advice to quit smoking among high risk male smokers in a community. Norsk Epidemiologi 1995; 5: A 22. 